\title{
Discussão da Posição de Calouras de Ciência da Computação
}

\author{
Karina Mochetti ${ }^{1}$, Raquel Bravo ${ }^{1}$, Luciana Salgado ${ }^{1}$, Carla Leitão ${ }^{2}$, \\ Camille Braga $^{1}$, Gabriela Hecksher ${ }^{1}$, Kayalla Pontes ${ }^{1}$ \\ ${ }^{1}$ Instituto de Computação - UFF \\ Niterói, Brasil \\ ${ }^{2}$ Departamento de Informática - PUC-Rio \\ Rio de Janeiro, Brasil \\ $\{$ kmochetti, raquel, luciana\}@ic.uff.br \\ cfarialinf.puc-rio.br \\ \{camillebns, gabrielahecksher, kayallapl\}@id.uff.br
}

\begin{abstract}
Resumo. A baixa participação de mulheres nas áreas de Computação é um fato preocupante já que diversidade em qualquer ambiente é de vital importância para sua evolução. No cenário de Tecnologia da Informação atual, em que os usuários passaram de consumidores para produtores de tecnologias e conteúdos digitais, este fato é ainda mais alarmante. Esse trabalho descreve a evolução de uma das atividades realizadas pelo Projeto \#include <meninas.uff $>$ na Universidade Federal Fluminense (UFF) com os alunos recém-matriculados no curso de Ciência da Computação nos últimos 3 semestres. O objetivo principal do evento é analisar a interação entre os alunos, principalmente com as calouras, nos primeiros dias de aula e promover uma discussão a respeito do baixo número de meninas no curso, abrindo espaço para elas se expressarem.
\end{abstract}

\begin{abstract}
The low participation of women in the computer's fields is a disturbing fact since diversity in any environment is vital to a good development, especially in technology where the role of end users is changing and they have gone from consumers to producers. This paper describes our project's activity at our university with the newly enrolled students in the Computer Science course in the last 3 semesters. Our goal is to analyze the interaction among students, especially girls, in the first days of school and promote a discussion about the low number of girls in the course, giving the opportunity for them to share their experiences.
\end{abstract}

\section{Introdução}

A diversidade de profissionais em todas as áreas é fundamental para que seja possível representarmos todos os indivíduos da sociedade moderna e, portanto, termos soluções mais adequadas aos problemas por ela enfrentados. Diante desta afirmativa é preocupante o baixo número de mulheres atuando na área de Tecnologias da Informação. Segundo o PNAD, em 2009 somente 18,84\% dos profissionais de Tecnologia da Informação (TI) eram mulheres [de Castro 2013].

A dificuldade de inclusão de mulheres em ambientes dominados por homens não é um problema atual, e traz à tona fatores importantes como o papel da mulher na sociedade, cujas regras são impostas e criadas por homens [de Beauvoir 1949]. Mais especificamente na área de TI, temos atualmente grandes congressos e grupos formados com o objetivo 
de estudar esse problema e tentar revertê-lo. Podemos citar, por exemplo, o congresso Grace Hopper Celebration of Women in Computing do Instituto Anita Borg [Gra ] e a Association for Women in Mathematics [AWM ].

Dentro desse contexto, diversos projetos nacionais foram criados, o principal deles sendo o Programa Meninas Digitais da Sociedade Brasileira da Computação (SBC) [Cristiano Maciel 2016]. Esse programa tem como objetivo motivar alunas do Ensino Médio e Fundamental a seguir carreira na área de Tecnologias da Informação. Ele já possui alguns parceiros como o Emili@as [emi ], o Cunhatã Digital [cun ], o \#include $<$ meninas.uff $>$ [Inc ] e também filiais na Região Sul e no Mato Grosso.

Este artigo descreve alguns resultado obtidos após mais de um ano de atividades realizadas pelo Projeto \#include $<$ meninas.uff $>$, do Instituto de Computação (IC) da Universidade Federal Fluminense (UFF). O projeto, além de trabalhar junto a alunas do Ensino Médio e Fundamental, busca atuar junto às alunas do Instituto, visando apoiar sua expressão e bem-estar como minoria de gênero, bem como evitar eventuais evasões em face deste tipo de problema.

\section{Objetivo}

Pela terceira vez, o Projeto \#include < meninas.uff $>$ organizou uma atividade com os alunos recém-inscritos no curso de Ciência da Computação da UFF, no contexto do Evento de Acolhimento dos Calouros, promovido pelo Diretório Acadêmico do curso [Mochetti et al. 2016]. No primeiro semestre de 2017 tivemos a participação de 5 alunas de 35 alunos no total (14\%). A mesma porcentagem foi verificada no primeiro semestre de 2016. Já no segundo semestre de 2016 tivemos uma porcentagem ainda menor com 4 alunas num total de 40 alunos (10\%).

O curso de Ciência da Computação da UFF existe desde 1985. Dos mais de 3000 alunos que já passaram pelo Instituto de Computação da UFF, somente $16 \%$ eram mulheres. Nota-se, contudo, que esse número já pequeno diminuiu muito nos últimos anos, chegando a valores alarmantes como a inscrição de somente uma menina em 2008 [Mochetti et al. 2016]. Com base nessa grave estatística, nosso projeto pretende contribuir para que esse problema seja contornado, motivando alunas do Ensino Médio e Fundamental a seguir carreira na área de TI e emponderando as alunas de graduação e pós-graduação já inclusas na área.

\section{Metodologia}

A estrutura da atividade foi mantida da mesma forma nos 3 períodos em que foi realizada [Mochetti et al. 2016]. Ela é composta de 3 partes: Primeiramente, os alunos participantes da atividade são posicionados em um grande círculo na intenção de que cada um se apresente para os demais. Ao final desta etapa pedimos a alguns dos participantes que dissessem o nome de algum outro colega, selecionado por nós, pesquisadoras.

$\mathrm{Na}$ segunda etapa os alunos foram divididos em grupos, com uma menina por grupo, se possível. No segundo período de 2016 a porcentagem de meninas foi tão baixa que foi necessário criar um grupo somente com meninos. A divisão é feita dando-se um número para cada menina na frente de todos, enquanto cada garoto ao receber seu número deveria procurar a menina correspondente. Desta forma, queremos que as meninas tenham a função indireta de liderança, sem que essa tenha sido imposta diretamente 
por nós. Nessa dinâmica cada grupo deve desvendar uma dica de uma caça ao tesouro baseada em uma Cifra de Substituição [Luciano 1987]. A cada período o tipo de cifra e a chave são alterados para evitar que os alunos que já realizaram a atividade em períodos anteriores passem alguma dica para os novos calouros.

A terceira etapa promove um debate aberto com os alunos sobre os motivos pelo qual o número de mulheres na área de Tecnologias da Informação ser cada vez mais baixo.

\section{Resultados}

Diferentemente do que ocorreu nas duas primeiras edições da acolhida, em 2017, no início de umas das atividades um aluno comentou que a atividade possivelmente estava relacionada com mulheres na computação já que éramos 2 professoras e 3 alunas. Podemos notar que um grupo de mulheres numa área tão masculina é incomum e, portanto, rapidamente chama a atenção e indica o motivo da atividade.

Na primeira etapa da atividade, percebemos o mesmo comportamento todas as vezes. Ao se posicionarem no círculo as alunas normalmente ficam todas juntas, próximas das professoras que estão organizando a atividade. No momento que elas se apresentam todos se calam para escutá-las, o que não acontece com seus colegas. O nome de todas também é rapidamente lembrado por todos, que em alguns casos já sabem o nome delas antes mesmo que estas se apresentarem. Normalmente as garotas que se afastam do grupo de meninas são as mais introvertidas e quietas. Este fato se manteve mesmo quando ocorreu uma interação prévia entre os calouros (a atividade realizada no primeiro semestre de 2017 ocorreu após alguns eventos sociais entre os alunos e os calouros).

$\mathrm{Na}$ segunda etapa da atividade percebemos que a maioria das alunas tem o papel com a dica retirado de sua mão rapidamente por algum dos garotos. Além disso, é possível notar em alguns grupos que apesar de tentar opinar ou recuperar o papel com a dica, elas por vezes são ignoradas pelos colegas, logo desistindo de participar ou tentando decifrar sozinha sem participação do seu time.

O grupo vencedor no terceiro período de atividade, no entanto, teve a aluna como líder o tempo todo. Ela não deixou que retirassem o papel de sua mão e decifrou rapidamente a mensagem praticamente sozinha, levando todos do seu time até o prêmio. Ela se mostrou independente e emponderada o tempo todo. Durante a última etapa da atividade, descobrimos que sua mãe é professora de matemática na universidade e que seu interesse pela área começou desde cedo. Por ter uma pessoa próxima na área, ela já imaginava que o número de meninas seria baixo.

Em todas as atividades percebemos que a presença de veteranos - mesmo que somente dois - coíbe os calouros, que têm receio de se expressar na etapa da atividade de discussão. Essa presença independe do sexo, já que veteranas também atrapalharam a boa evolução da atividade. Apesar disso, as meninas sempre parecem interessadas e dispostas a compartilhar suas histórias e experiências. Percebemos no discurso da maioria que apesar de saberem da baixa porcentagem de mulheres no curso elas ainda se assustam com o baixo número assim que sai a lista de aprovados.

Atualmente temos no Projeto \#include $<$ meninas.uff $>$ duas alunas que participaram da atividade como calouras no primeiro semestre de 2016. Segunda elas, após a apresentação do Projeto \#include $<$ meninas.uff $>$, muitos meninos comentaram que 
acharam ótima elas terem compartilhados suas experiências e que não tinham ideia de como era a sensação de ser uma menina na área de TI. Além disso, elas se sentem felizes e surpresas ao verem mulheres bem sucedidas na área e ao terem o apoio de um projeto dedicado somente a elas. Assim, podemos concluir que o projeto está tendo um efeito positivo na inclusão de meninas nos primeiros dias de aula.

\section{Conclusão}

A análise das recorrências em três edições do acolhimento dos calouros de ciência da computação visando a reflexão sobre a posição das meninas no curso e na carreira revelou, através de inúmeras evidências verbais que:

- Desde a escolha da carreira as meninas sentem-se desmotivadas pela sociedade (inclusive pela família) a procurar carreira nas ciências exatas. Isto reforça a importância dos projetos de incentivo à carreira no Ensino Médio e Fundamental, mas também revela que aquelas que escolhem a carreira o fazem sob a pressão da minoria e podem necessitar de apoio para reafirmar e permanecer firmes em sua escolha ao longo do estudo na graduação.

- O incentivo à inserção de alunas que já participaram do acolhimento no Projeto \#include $<$ meninas.uff $>$ é forte incentivo para a permanência na carreira além de exemplo e motivação para as calouras que encontram nessas veteranas exemplos de sucesso na opção.

- O papel dos veteranos na atividade, independente de gênero, é hoje mais de obstáculo do que de colaboração. O desafio, para edições futuras, é a definição de ações que permitam que os veteranos se transformem em aliados do projeto.

Trabalhos futuros mostram-se interessantes em relação ao acompanhamento da evolução das participantes do acolhimento no curso de Ciência da Computação e no levantamento mais aprofundado da percepção dos meninos quanto à atividade realizada.

\section{Referências}

Association for Women in Mathematics. sites.google.com/site/awmmath.

Cunhatã Digital. www. facebook.com/cunhantadigital.

Emili@as.https://www.facebook.com/emiliasarmacaoembits.

Grace Hopper Celebration of Women in Computing. ghc . anitaborg • org.

\#include $<$ meninas.uff $>$. www. facebook. com/include.meninas. uff.

Cristiano Maciel, S. A. B. (2016). Programa meninas digitais - ações para divulgar a computação para meninas do ensino médio. In Computer on the Beach.

de Beauvoir, S. (1949). O Segundo Sexo. Nova Fronteira.

de Castro, B. G. (2013). Afogados em contratos: o impacto da flexibilização do trabalho nas trajetórias dos profissionais de TI. PhD thesis, UNICAMP.

Luciano, D. G. P. (1987). Cryptology: From caesar ciphers to public-key cryptosystems. The College Mathematics Journal, 18.

Mochetti, K., Salgado, L., Zerbinato, A. V., Souza, B. L., and Avelino, M. R. E. (2016). Ciência da computação também é coisa de menina! Women in Information Technology at Brazilian Computer Society Congress. 